\title{
Salivary Gland Epithelial Myoepithelial Carcinoma
}

National Cancer Institute

\section{Source}

National Cancer Institute. Salivary Gland Epithelial Myoepithelial Carcinoma. NCI

Thesaurus. Code C35701.

A carcinoma that arises from the salivary glands, most often the parotid gland. It presents as a slow growing and painless mass. It is characterized by the presence of duct-like structures lined by two layers of cells, an inner layer composed of epithelial-type cells and an outer layer composed of clear, myoepithelial-type cells. 